\title{
Effects of gradual volume loading on left ventricular diastolic function in dogs: implications for the optimisation of cardiac output
}

\section{Volume loading and diastolic function}

\author{
J Fragata, J C Areias
}

\begin{abstract}
Background-Volume loading is commonly used to adjust preload and optimise cardiac output. It is difficult to monitor preload at the bedside because filling affects ventricular diastolic function and consequently end diastolic pressure, which is the variable used to monitor preload.

Objective-To assess the effects of gradual volume loading on the different components of left ventricular diastolic function-filling velocities, relaxation, and chamber compliance-to identify how excessive loading produces diastolic dysfunction.
\end{abstract}

Methods and results-Eight mongrel dogs, anaesthetised and mechanically ventilated with both the chest and the pericardium closed, were studied during basal conditions (B), during gradual volume loading with physiological saline$5 \mathrm{ml} / \mathrm{kg}$ (VL5), $10 \mathrm{ml} / \mathrm{kg}$ (VL10), and $15 \mathrm{ml} / \mathrm{kg}$ (VL15) -and during infusion of isosorbide dinitrate $(10 \mathrm{~g} / \mathrm{kg} / \mathrm{min})$ started after the VL15 load was achieved. Dogs were monitored haemodynamically and by transthoracic Doppler echocardiography to assess peak modal velocities of the $E$ and $A$ waves, E/A ratios, and the deceleration time of the $E$ wave. $M$ mode recordings of aligned mitral and aortic valve motion were also obtained to calculate the isovolumic relaxation time. Effects of volume loading on ventricular diastolic function seemed to occur in two phases. Small and moderate volume loads (VL5 and VL10) promoted early ventricular filling, increasing $E$ wave velocities, improving the mean (SD) E/A ratio from $1.95(0.3)(B)$ to $2.0(0.27)$ (VL5) and 2.6 $(0 \cdot 3)(V L 10)(P<0.00005)$, prolonging the $E$ wave deceleration time, and only slightly increasing ventricular diastolic pressures. These changes suggest an improvement in ventricular compliance. Extreme volume loads (VL15) produced an abrupt reduction in early ventricular filling, which was transfered to late in diastole, by decreasing $E$ wave velocity, by increasing $A$ wave velocity, and by decreasing E/A ratio from $2.6(0 \cdot 3)$ (VL10) to $0.8(0.05)$ (VL15) $(P<0.00005)$. The $E$ wave deceleration time was shortened and left ventricular diastolic pressures were much increased, all suggesting a deterioration in chamber compliance. All these restrictive changes were promptly reversed by the perfusion of isosorbide dinitrate. The isovolumic relaxation time steadily increased with volume loading. Conclusions-Small and moderate volume loads improved ventricular diastolic function by promoting early ventricular filling and increasing ventricular compliance. Extreme volume loads promptly induced a diastolic restrictive pattern, tranferring filling to the second part of diastole (increasing dependence on atrial contraction) and reducing ventricular compliance. These changes in ventricular diastolic function were independent of simultaneously measured haemodynamic systolic performance and were promptly reversed by isosorbide dinitrate, which after extreme loading promoted early filling, myocardial relaxation, and improved chamber compliance.

(Heart 1996;75:352-357)

Keywords: diastolic ventricular function; volume loading

Volume loading is the first intervention used to optimise cardiac output in critically ill patients after open heart surgery. ${ }^{12}$ Volume loading is aimed to expand ventricular preload to increase stroke volume and cardiac output. This relation, in clinical everyday use, is based on the Frank-Starling law of the heart, that relates fibre distension in diastole (preload) to systolic work - volume displacement, against a given resistance (afterload) for a given level of myocardial contractility.

Ideal myocardial fibre distension induced by volume loading of the ventricles is difficult to monitor in the critically ill. This is particularly true in patients after open heart surgery in whom changes in both the systolic ${ }^{3-5}$ and the diastolic ${ }^{6-8}$ ventricular function are known to take place during the first hours after the operation and to affect ventricular pressurevolume relations to an uncertain extent. Left ventricular filling is complex and known to have multifactorial determinants-moment loading conditions, myocardial relaxation state, ventricular compliance, heart rate, and atrial contraction ${ }^{9}{ }^{10}$ : these must all be taken into consideration in order to understand both the process and the end result of ventricular filling in response to gradual volume loading. ${ }^{11}$

Optimisation of cardiac output depends firstly on adequate filling of the ventricles. 
This is usually obtained by trial and error by assessing filling pressures and the effects produced upon systolic performance. Filling conditions ought to be monitored carefully as overfilling is known to produce deleterious effects on systolic performance of the ventricles. ${ }^{12} 13$ The present study was designed to follow the effects of gradual volume loading on left ventricular diastolic filling patterns, assessed by Doppler-echocardiography, by relating them to simultaneous systolic events, in order to detect early diastolic dysfunction shifting points that occur with extreme loading conditions, even before such shifts could affect systolic performance.

\section{Methods}

ANIMAL PREPARATION

Eight mongrel dogs $(12 \cdot 0(2 \cdot 7) \mathrm{kg})$ were used for the study. Their care complied with the Principles of Laboratory Animal Care, formulated by the National Society for Medical Research, and the Guide for the Care and Use of Laboratory Animals, prepared by the National Academy of Sciences and published by the National Institutes of Health (NIH Publication $\mathrm{N}^{\circ} 86-23$, revised 1985).

Dogs lay supine on a heating pad and were anaesthetised with intravenous pentobarbitone $(30 \mathrm{mg} / \mathrm{kg})$. They were mechanically ventilated with room air using a Palmer animal ventilator (tidal volume of $12 \mathrm{ml} / \mathrm{kg}$ at a rate of 20/minute to keep arterial $\mathrm{PCO}_{2}$ between 30 and $40 \mathrm{~mm} \mathrm{Hg}$ ). The electrocardiogram was continuously monitored, a $6 \mathrm{~F}$ pigtail catheter was advanced retrogradely from the femoral artery into the left ventricle, a double lumen 7F Swan-Ganz thermodilution catheter was introduced through the femoral vein and placed in the pulmonary artery and a $6 \mathrm{~F}$ pressure line was placed in the descending aorta, through the femoral artery. Pressures were measured in the aorta, the left ventricle, and the pulmonary artery, by using fluid filled catheters and Gold transducers zeroed at mid chest level and a Datascope 2000A cardiac monitor.

Cardiac output was evaluated by thermodilution using an Arrow Al thermodilution computer and a Swan-Ganz thermodilution catheter. Values were automatically computed from dilution curves obtained with triplicate injections of $5 \mathrm{ml}$ physiological saline, kept in ice and delivered by hand and at a temperature of $4^{\circ} \mathrm{C}$, into the right atrium. Haemodynamic data were recorded in absolute values and then related to the dog's body surface area where appropriate. Body surface area was calculated by the formula:

$$
\text { BSA }=0.112 \times \text { weight }^{2 / 3}(\mathrm{~kg})
$$

and left ventricular stroke work index was calculated according to the formula:

$$
\begin{aligned}
\text { LVSWI }= & (\text { MAP }- \text { PCW pressure }) \times \\
& \text { SVI } \times 0.0136 .
\end{aligned}
$$

Doppler echocardiograms were obtained using a $5 \mathrm{MHz}$ probe and an Aloka SSD-720 echo machine and recorded for future reading in VHS videotapes $(50 \mathrm{~mm} / \mathrm{s}$ speed). Pulsed cross sectional echo-Doppler recordings of mitral inflow were obtained with the transducer aligned with the long axis of the ventricle and the sample volume was placed at the valve ring level. Transthoracic recordings of five consecutive cycles were made during short periods of apnoea and after the dogs were momentarily positioned in the left lateral decubitus position, in order to improve the echocardiographic window and to ensure accurate echo recordings. The electrocardiographic signal was continuously recorded and $M$ mode recordings of the aligned mitral and aortic valve motion were obtained for calculation of the isovolumic relaxation time (IRT).

Although $M$ mode measurements of ventricular dimensions were taken during volume loading they were not systematically registered because the unpredictable variation in the chamber shape suggested they would be of little use for judging volume changes from linear dimensions.

The tapes were read blindly. Peak modal velocities of the $E$ wave and $A$ wave of the Doppler mitral flow profile were measured in $\mathrm{cm} / \mathrm{s}$. The E/A ratio was calculated and the deceleration time of the $E$ wave was measured in $\mathrm{ms}$ from the peak of $\mathrm{E}$ wave to its nadir on the baseline. Occasionally, when the A wave started before the $\mathrm{E}$ wave had reached the zero line, the $\mathrm{E}$ wave deceleration time had to be measured by extrapolating its descent and estimating its nadir on the baseline.

Means and standard deviations of the mean were compared by Student's paired $t$ test and linear regression analysis was performed where appropriate. Values of $P<0.05$ were regarded as statistically significant.

\section{EXPERIMENTAL DESIGN}

Dogs were studied during basal conditions (B) and during gradual volume loading with physiological saline, $5 \mathrm{ml} / \mathrm{kg}$ (VL5), $10 \mathrm{ml} / \mathrm{kg}$ (VL10), and $15 \mathrm{ml} / \mathrm{kg}$ (VL15). Saline loads were infused for up to 5 minutes and measurements were made after allowing 10 minutes for haemodynamic stabilisation. After the 15 $\mathrm{ml} / \mathrm{kg}$ volume load (VL15) an intravenous infusion of isosorbide dinitrate $(10 \mathrm{~g} / \mathrm{kg} / \mathrm{min}$ (IDN)) was given and measurements were repeated after 10 minutes of haemodynamic stabilisation.

Dogs were killed by a bolus injection of potassium chloride, and the placement of all intracardiac lines was checked.

\section{Results}

Progressive volume loading simultaneously affected haemodynamics and ventricular filling and relaxation. It eventually induced a restrictive filling pattern that was reversed by IDN. These complex changes are analysed separately:

HAEMODYNAMIC VARIATION (TABLE 1)

Heart rate showed no significant variation from baseline to maximal volume loading. Left ventricular systolic pressure increased gradu- 
Table 1 Haemodynamic data

\begin{tabular}{|c|c|c|c|c|c|}
\hline Variables & Basal & $V L 5(\mathrm{ml} / \mathrm{kg})$ & $V L 10(\mathrm{ml} / \mathrm{kg})$ & $V L 15(\mathrm{ml} / \mathrm{kg})$ & $D N I$ \\
\hline Heart rate (beats/min) & $157.4(23.8)$ & $150.0(21.4)$ & $144 \cdot 3(24 \cdot 1)$ & $139 \cdot 4(19 \cdot 3)$ & $\begin{array}{l}169 \cdot 0(24 \cdot 3) \\
(P=0 \cdot 006)\end{array}$ \\
\hline LV SP (mm Hg) & $121.4(24.9)$ & $129 \cdot 7(20 \cdot 8)$ & $138 \cdot 7(26 \cdot 3)$ & $144 \cdot 6(18 \cdot 3)$ & $\begin{array}{l}161 \cdot 0(22 \cdot 0) \\
(P=0.001)\end{array}$ \\
\hline LV DP (mm Hg) & $1.5(3 \cdot 2)$ & $\begin{array}{r}4.2(3.5) \\
(P=0.02)^{\star}\end{array}$ & $\begin{array}{c}7.8(5.9) \\
(P=0.003) \dagger\end{array}$ & $\begin{array}{c}15.8(6.0) \\
(P=0.0002) \ddagger\end{array}$ & $\begin{array}{c}10.3(4 \cdot 7) \\
(P=0.005)\end{array}$ \\
\hline $\begin{array}{l}\text { Cardiac index }\left(1 / \mathrm{min} / \mathrm{m}^{2}\right) \\
\text { LV stroke work }\left(\mathrm{g} / \mathrm{min} / \mathrm{m}^{2}\right)\end{array}$ & $\begin{array}{r}1 \cdot 9(0 \cdot 6) \\
12 \cdot 7(4 \cdot 2)\end{array}$ & $\begin{array}{r}2 \cdot 6(1 \cdot 1) \\
22 \cdot 9(9 \cdot 8) \\
(P=0.01)^{\star}\end{array}$ & $\begin{array}{c}3.4(0.7) \\
30.2(8.6) \\
(P=0.006) \dagger\end{array}$ & $\begin{array}{c}4.0(0.5) \\
38.5(13.2) \\
(P=0.025) \ddagger\end{array}$ & $\begin{array}{c}4 \cdot 3(1 \cdot 3) \\
41 \cdot 0(14 \cdot 4)\end{array}$ \\
\hline
\end{tabular}

Values are means (SD).

*Compared with basal; $†$ compared with VL5; $\ddagger$ compared with VL10; §compared with VL15.

LV SP, left ventricular systolic pressure; LV DP, left ventricular diastolic pressure.

ally with volume loading, from 121.4 (24.9) (B) to $129.7(20.8)$ (VL5) to $138.7(26.3)$ (VL10) and to $144.6(18 \cdot 3) \mathrm{mm} \mathrm{Hg}$ (VL15): these changes did not reach statistical significance. Left ventricular diastolic pressure increased gradually, from $1.5(3.2)$ (B) to 4.2 (3.5) (VL5) $\mathrm{mm} \mathrm{Hg}(\mathrm{P}=0.02)$ and to $7 \cdot 4$ (5.9) (VL10) $(P=0.003)$; it increased dramatically with extreme volume loading, from $7 \cdot 4(5 \cdot 9)(\mathrm{VL} 10)$ to $14.6(6 \cdot 0) \mathrm{mm} \mathrm{Hg}$ (VL15) $(\mathbf{P}=0.0005)$.

Cardiac index increased steadily for all levels of volume loading, from $1.9(0.6)$ (B) to $2.6(1 \cdot 1)$ (VL5) to $3.4(0.7)(\mathrm{VL} 10)$ and to 4.0 $(0.5) \mathrm{l} / \mathrm{min} / \mathrm{m}^{2}$ (VL15); these changes did not reach statistical significance. Left ventricular stroke work index increased from $12 \cdot 7(4 \cdot 2)$ (B) to $22.9(9.8)$ (VL5) $(\mathrm{P}=0.01)$ to 30.2 $(8.6)(\mathrm{VL10})(\mathrm{P}=0.006)$ and to $38.5(13.2)$ $\mathrm{g} / \mathrm{min} / \mathrm{m}^{2}(\mathrm{VL} 15)(\mathrm{P}=0.025)$.

EARLY FILLING WAVE (E WAVE) (TABLE 2)

During volume loading peak modal $E$ wave velocity increased from $76(6.3)$ (B) to 84.2 $(9.7)$ (VL5) (NS) and to $99 \cdot 2(9.2) \mathrm{cm} / \mathrm{s}$ (VL10) $(P=0.01)$. Then it decreased to $72 \cdot 7$ $(8 \cdot 1) \mathrm{cm} / \mathrm{s}$ during the extremely high volume loading (VL15) $(P=0.00)$.

LATE FILLING WAVE (A WAVE) (TABLE 2)

Peak modal A wave velocities did not vary significantly for the first two volume loads, changing from $41.5(6.1)$ (B) to $41.7(8.0)$ (VL5) (NS) to $38 \cdot 8(5 \cdot 7)$ (VL10) (NS). Then it increased significantly from $38.8(5.7)$ (VL10) to $85.8(8.0) \mathrm{cm} / \mathrm{s} \quad(\mathrm{VL15}) \quad(\mathrm{P}=$ 0.00005).

E/A RATIO (TABLE 2)

The E/A ratio increased from $1.95(0.3)(B)$ to
$2.0 \quad(0.27) \quad(\mathrm{VL} 5)$ and $2.6 \quad(0.3) \quad(\mathrm{VL} 10)$ $(\mathbf{P}<0.00005)$, to decrease to $0.8(0.05)$ $(P<0.00005)$ with extreme volume loading (VL15). E/A ratio, as a global index of the filling conditions, correlated with left ventricular diastolic pressure, $r=-0.61(\mathrm{P}<0.001$, $\mathrm{n}=24)$ and with IRT, $r=-0.70$ $(\mathrm{P}<0.001, \mathrm{n}=24)$.

E WAVE DECELERATION TIME (EWDT) (TABLE 2) Variation in EwDT during volume loading paralleled $\mathrm{E}$ wave velocity variation, increasing from $101.8(14.9)$ (B) to $104.8(8 \cdot 7)$ (VL5) to $132.0(26.3)(\mathrm{VL10})(\mathrm{P}=0.04)$ and decreasing to $86.2(14.7) \mathrm{ms} \quad(P=0.003)$ with extreme volume loading (VL15). EwDT correlated well with left ventricular diastolic pressure $(r=-0.54(\mathrm{P}<0.01, \mathrm{n}=24)$.

ISOVOLUMIC RELAXATION TIME (IRT) (TABLE 2) IRT increased significantly from $75.4(6.6)$ (B) to $86.4(5 \cdot 2)(\mathrm{VL} 5)(\mathrm{P}=0.005)$ to 100.6 $(6.6)(\mathrm{VL10})(\mathrm{P}=0.003)$ and to $122.6(14.6)$ ms (VL15) $(P=0.022)$ during gradual volume loading. Left ventricular systolic pressure increased along with each volume load and correlated with IRT $(r=0.56, \mathrm{P}<0.01, \mathrm{n}=$ $30)$, while the heart rate slowed down, though not significantly, from $157.4(23.8)$ (B) to $139.4(19 \cdot 3)$ beats/min (VL15).

EFFECTS OF IDN ON DIASTOLIC FUNCTION INDICES AFTER EXTREME VOLUME LOADING (TABLES 1 AND 2)

IDN was given after the extreme $15 \mathrm{ml} / \mathrm{kg}$ volume load was reached. It reduced IRT from $122.6(14.6)(\mathrm{VL} 15)$ to $55.7(6.0) \mathrm{ms}$ (IDN) $(\mathbf{P}=0.023)$. It also decreased left ventricular diastolic pressure from $15.8(6.0)$ (VL15) to $10.3(4.7) \mathrm{mm} \mathrm{Hg}(\mathrm{IDN})(\mathrm{P}=0.0005)$ and

Table 2 Doppler echocardiographic data

\begin{tabular}{|c|c|c|c|c|c|}
\hline Variables & Basal & $V L 5(\mathrm{ml} / \mathrm{kg})$ & $V L 10(\mathrm{ml} / \mathrm{kg})$ & $V L 15(\mathrm{ml} / \mathrm{kg})$ & $D N I$ \\
\hline E wave velocity $(\mathrm{cm} / \mathrm{s})$ & $76 \cdot 0(6 \cdot 3)$ & $84 \cdot 2(9 \cdot 7)$ & \multirow{2}{*}{$\begin{array}{c}99 \cdot 2(9 \cdot 2) \\
(P=0.01) \dagger \\
38.8(5.7)\end{array}$} & \multirow{5}{*}{$\begin{array}{c}72.7(8.1) \\
(P=0.001) \ddagger \\
85.8(8.0) \\
(P=0.00005) \ddagger \\
0.8(0.05) \\
(P<0.00005) \ddagger \\
86.2(14.7) \\
(P=0.003) \ddagger \\
122.6(14.6) \\
(P=0.022) \ddagger\end{array}$} & $96 \cdot 3(11 \cdot 0)$ \\
\hline A wave velocity $(\mathrm{cm} / \mathrm{s})$ & $41 \cdot 5(6 \cdot 1)$ & $41 \cdot 7(8 \cdot 0)$ & & & \multirow{4}{*}{$\begin{array}{c}43.3(2.9) \\
(P=0.005) \rrbracket \\
2.2(0.02) \\
(P=0.0007) \S \\
119.0(3.6) \\
(P=0.022) \S \\
55.7(6.0) \\
(P=0.023) \S\end{array}$} \\
\hline $\mathrm{E} / \mathrm{A}$ ratio & $1.92(0.3)$ & $2.0(0.27)$ & $\begin{array}{c}2.6(0.3) \\
(\mathrm{P}<0.00005) t\end{array}$ & & \\
\hline EWDT (ms) & $101 \cdot 8(14.9)$ & $104 \cdot 8(8 \cdot 7)$ & $\begin{array}{l}132 \cdot 0(26 \cdot 3) \\
P=0.04) t\end{array}$ & & \\
\hline IRT (ms) & $75 \cdot 4(6 \cdot 6)$ & $\begin{array}{c}86 \cdot 4(5 \cdot 2) \\
(P=0.005)^{\star}\end{array}$ & $\begin{array}{l}100.6(6.6) \\
(P=0.003) \dagger\end{array}$ & & \\
\hline
\end{tabular}

Values are means (SD)

*Compared with basal; †compared with VL5; łcompared with VL10; §compared with VL15. 
increased left ventricular systolic pressure from the VL15 value of $144.6(18 \cdot 3)$ to 161.0 $(22 \cdot 0) \mathrm{mm} \mathrm{Hg}$ (IDN) $(\mathrm{P}=0 \cdot 001)$. EwDT increased from $86.2(14 \cdot 7)$ (VL15) to 119.0 (3.6) $\mathrm{ms}(\mathrm{IDN})(\mathrm{P}=0.022)$ and $\mathrm{E} / \mathrm{A}$ filling ratio from $0.8(0.05)$ (VL15) to $2.2(0.02)$ (IDN) $(\mathbf{P}=0.0007)$.

IDN reversed the restrictive filling pattern imposed by extreme volume loading, by improving both relaxation and chamber compliance and by promoting early ventricular filling.

\section{Discussion}

Our study demonstrates the effects of gradual volume loading upon different components of left ventricular diastolic function-filling velocities, relaxation, and chamber compliance-and the simultaneously produced haemodynamic variation. The effects of volume loading seemed to be biphasic: small and moderate volume loads promoted early ventricular filling, improved ventricular compliance, and exerted no effect on ventricular diastolic pressures. Extreme volume loads abruptly reduced early filling, transferring it to late in diastole, and to dependance on atrial contraction. Volume loading also decreased chamber compliance and increased ventricular diastolic pressure. At the same time isovolumic relaxation was steadily prolonged for all levels of volume loading. These changes in diastolic function took place at the same time as haemodynamic systolic variables, such as the cardiac index and ventricular stroke work, increased steadily with additional volume loading.

When we assessed the effects of IDN, a commonly used vasodilator, on extreme loading conditions we found that it reversed the pattern of restrictive diastolic dysfunction induced by excessive loading, promoting early filling, chamber compliance, and myocardial relaxation.

\section{DISCUSSION OF METHODS}

We used anaesthetised mechanically ventilated, closed chest dogs under stable homoeostatic conditions. The effects of the anaesthetic, pentobarbitone, on ventricular function are well established ${ }^{14}$ and the possible effects of ventilation on ventricular filling were abolished by taking measurements only during post-expiratory apnoea.

Doppler echocardiography is an established non-invasive method of assessing ventricular diastolic function ${ }^{15}{ }^{16}$ but because many factors interact simultaneously to influence ventricular relaxation, Doppler filling patterns must be interpreted cautiously and considered, as we have done, in the light of simultaneous haemodynamic variation. ${ }^{17-19}$

Heart rate was allowed to fluctuate in our experiments, although it is known to affect both relaxation ${ }^{20-22}$ and ventricular filling. ${ }^{2324}$ Heart rate variation in our series was small and so unlikely to have affected relaxation conditions. In our experimental group, and like others, ${ }^{25}$ we did not find any correlation between heart rate and either IRT or filling velocities.

For haemodynamic monitoring of the filling conditions, we preferred to use the middiastolic left ventricular pressure plateau that is related to the equalisation of both the left atrial and the left ventricular diastolic pressure at the end of the early filling phase of diastole, ${ }^{26}$ although we know that it relates more to the end result of early filling rather than to the early part of diastole. This choice may be open to criticism but it was made because left atrial pressure could not be measured directly and so an accurate measurement of the transmitral haemodynamic gradient was not available. Also, we did not think that pulmonary wedge pressure would have been an accurate method to estimate left atrial pressure and indirectly to assess left ventricular filling conditions. ${ }^{27}$

Gradual volume loading, as used in our series, allows for a better understanding of the progressive changes that occur simultaneously in diastolic and systolic ventricular function while volume expansion is taking place in conditions that mimic the clinical situation.

\section{VOLUME LOADING EFFECTS ON VENTRICULAR} RELAXATION

Relaxation is affected by moment loading conditions. Loads applied early in diastole are called relaxation loads and are known to accelerate the relaxation process, ${ }^{928}$ while loads applied late in diastole are called contraction loads and are known to delay relaxation (directly if they are pressure loads or indirectly if they are volume loads, and they secondarily affect the afterload conditions). This is the case for in vivo models such as the one we used. ${ }^{21}{ }^{29-31}$

Sequential volume infusion in our series is an example of a combined direct distension load and an indirect tension load acting in sequence during both the contraction and relaxation phases of the cardiac cycle. These loads determine the increases and decreases in relaxation time respectively and contribute to the so-called auxotonic regulation of the relaxation process. ${ }^{9}$ The prolongation of IRT, which reflects the relaxation delay, that we found for all levels of volume loading in our series, sums the effects of these different loading factors on relaxation. This is borne out by the positive correlation found between IRT and left ventricular peak systolic pressure (contraction load) and by the negative correlation found between IRT and systemic vascular resistance (relaxation load) in our series.

\section{VOLUME LOADING EFFECTS ON VENTRICULAR} FILLING

Left ventricular filling is a complex phenomenon that takes place during an early $(85 \%$ of the filling volume) and a late filling phase ( $15 \%$ of the filling volume), which are separated by the diastasis pause. Filling is known to be a multifactorial process determined by moment loading conditions, myocardial relaxation state, ventricular compliance, heart rate, and atrial contraction. ${ }^{910} 3032$

Several groups have assessed the effects of 
volume loading 11263132 and the effects of volume unloading ${ }^{11} 263334$ upon diastolic function indices. Our results show, for the first time, a biphasic pattern of diastolic function, characterised initially by improved filling conditions with small to moderate volume loading, followed by a restrictive filling pattern induced by extreme loading that was detected even before systolic function started to deteriorate as a consequence of "overfilling"-that is, even before the start of the decline in the Starling curve.

Small and moderate volume loads (5 and 10 $\mathrm{ml} / \mathrm{kg}$ ) increased the early filling velocity (E wave) and kept the late filling velocity (A wave) constant because they increased the left atrial to left ventricular pressure gradient that initiates early ventricular filling. ${ }^{26}{ }^{30}$ This haemodynamic effect was bigger than the simultaneously induced prolongation of IRT that we and others ${ }^{32}$ observed, which tends to reduce early filling velocity. EwDT, a variable related to ventricular compliance, became longer as loading increased. An indication that ventricular compliance increased in parallel is the increase in diastolic volume with only a small increase in diastolic pressure. Our results are similar to those of Nishimura et al ${ }^{11}$ in moderately volume loaded patients, except that they found that EwDT was reduced. The reason for this important difference may lie in the fact that they studied coronary patients, in whom ventricular compliance is reduced, ${ }^{10}$ and that in their study filling pressures were increased by $20 \%$, which corresponds only to our extreme loading conditions.

Extreme volume loading (15 ml/kg) reduced early filling velocity, increased late filling velocity (A wave velocity), and reduced EwDT whereas left ventricular diastolic pressure was significantly increased, suggesting deterioration in ventricular compliance. This corresponds to a restrictive filling pattern of diastolic dysfunction ${ }^{25}$ in which filling was transferred to the second half of diastole and which depended on atrial contraction, but which still maintained the filling volumes and an entirely normal systolic performance, with increases in cardiac index and ventricular stroke work. These results accord with those of Ishida $e a^{30}$ and Nishimura et al ${ }^{31}$ in dogs in which extreme volume loading induced similar restrictive diastolic filling patterns.

Alternatively we might infer that this biphasic response of the early filling velocity to volume loading is related to changes in the preceding isovolumic relaxation phase, which is a well known determinant of ventricular filling. The response of isovolumic relaxation velocity to increases in load was also recently shown to be biphasic in a recent study by Leite-Moreira and Gillebert. ${ }^{35}$ They showed that the biphasic response was related to the relative load, assessed as a percentage of the peak isovolumic pressure. Our failure to show a biphasic pattern of variation for the isovolumic relaxation time too is probably due to the large variation imposed by different volume loading conditions on aortic valve closing and mitral valve opening times.
VOLUME LOADING EFFECTS ON VENTRICULAR COMPLIANCE

Chamber compliance is known to depend on myocardial modular elasticity, diastolic volume, ventricular mass, shape of the cavity, and diastolic interdependence mechanisms mediated by the closed pericardium. ${ }^{36} 37$ EwDT relates to ventricular compliance ${ }^{101538}$ and varied in our series with volume loading, increasing with small and moderate loads, in favour of early filling, and decreasing with extreme loads. The reason for these changes, confirmed by others but only for extreme loads, ${ }^{1131}$ lies not only in the increase in diastolic volume but also in changes of cavity shape mediated by diastolic interdependence mechanisms with the right ventricle, septum, and pericardium ${ }^{39}$ that occur because the right ventricle is being simultaneously loaded while other determinants remain constant. Because of the curvilinear shape of the pressure-volume curve, extreme volume loading produced a sudden leftward shift on the curve, accounting for the dramatic increase in ventricular diastolic pressures, which were found to correlate negatively with EwDT.

\section{EFFECTS OF IDN ON FILLING CONDITIONS}

AFTER EXTREME VOLUME LOADING

The effects of IDN on the restrictive filling pattern induced by extreme loading were dramatic and characterised by improved relaxation (IRT decrease), improved ventricular pressure-volume relations (prolongation of EwDT and reduction in ventricular diastolic pressures), and reversal of the restrictive filling pattern and the E/A ratio. These actions contrast with the apparently negative effects of nitrates on diastolic ventricular function, ${ }^{113440-42}$ which are similar to pure haemodynamic preload reduction $^{263133}$ and are characterised by reduction in early filling velocity and decreases in EwDT. In our series the clearly favourable effect of IDN on diastolic function has to do with the fact that, unlike other studies, nitrates were used only when extreme loading conditions were achieved and not when haemodynamic variables were normal. The mechanisms responsible may have been primarily a preload reduction effect $^{43}$ that induced a favourable ventricular pressure-volume curve shift ${ }^{44} 45$ and eventually a direct myocardial effect with improved relaxation (IRT decreased). This effect could either be direct or depend on induced myocardial vasodilatation that could act as an intrinsic load to enhance relaxation ${ }^{9}$ or even correspond to a vasodilator effect that would favour sub-endocardial perfusion in a volume loaded, distended ventricle with subendocardial ischaemia and improve relaxation compliance and filling.

\section{CLINICAL IMPLICATIONS}

Our study allowed for a better understanding of the gradual volume loading process, as used to optimise cardiac performance in critically ill patients. Transition from normal diastolic function to abnormal relaxation and filling was demonstrated and proved to be sudden and to occur with high filling pressures, even before 
any haemodynamic systolic deterioration could occur. The true restrictive filling pattern that was induced by extreme loading was easily reversed by nitrate therapy, allowing for new pressure-volume relation and more room for volume optimisation.

Correlation between Doppler derived data and haemodynamic measurements was poor in our series as in others, but was present between the $\mathrm{E} / \mathrm{A}$ ratio and ventricular diastolic pressures.

Combination of both diastolic ventricular function data assessed by Doppler echocardiography (namely transoesophageal) and traditional haemodynamic data might be useful to monitor changing filling conditions (for example, after open heart surgery) and to optimise systolic function in relation to volume loading as well as to guide fluid therapy in any critically ill patient.

We thank Dr A Leite-Moreira for reviewing the text and for useful suggestions and Professor J Henrique Barros for performuseful suggestions and Professor J Henrique Barros for performing the statistical analysis of all the data in the paper.
support: JNICT, project no PMCT/C/SAU/979/90).

1 Weisel RD, Burns RJ, Baird RJ, et al. Optimal post-operative volume loading $f$ Thorac Cardiovasc Surg 1983;85: volume

2 Burrows FA, Williams WG, Teoh KH, et al. Myocardial performance after repair of congenital heart defects in infants and children. $\mathcal{F}$ Thorac Cardiovasc Surg 1988;96: 548-6.

3 Philips HR, Carter JE, Okada RD, et al. Serial changes in left ventricular ejection fraction in the early hours afte aortocoronary bypass grafting. Chest $1983 ; 83: 28-34$.

$4 \mathrm{Harpole}$ DH, Jones RH. Serial assessment of ventricular performance after valve replacement for aortic stenosis. $\mathcal{F}$ Thorac Cardiovasc Surg 1990;99:645-50.

5 Breisblat WM, Stein FKL, Wolfe CJ, et al. Acute myocardial dysfunction and recovery: A common occurrence after coronary bypass surgery. F Am Coll Cardiol 1990;15. 1261-9.

6 Rinder CS, Wheeler LR, Alpern WD. Pulsed Doppler assessment of diastolic function before and after cardiopulmonary bypass. Anesthesiology 1988;69:A2

7 Wehlage R, Bohrer H, Ruffmann K. Impairement of left ventricular diastolic function during coronary artery bypass grafting. Anesthesia 1990;45:549-51.

8 Fragata J. Left ventricular diastolic function after open heart surgery. PhD thesis, Faculty for Medical Sciences of the New University of Lisbon, 1991:53-74

9 Brutsaert D, Sys S. Relaxation and diastole of the heart. Physiol Rev 1989;69:1228-315.

10 Bessen M, Gardin J, Evaluation of left ventricular diastolic function. Cardiol Clin 1990;8:315-32.

11 Nishimura RA, Abel MD, Hatle LK, et al. Relation of pulmonary vein to mitral flow velocities by transeosphageal Doppler echocardiography. Circulation 1990 81:1488-97.

12 Mangano DR, Van Dyke DC, Ellis RJ, et al. The effect of increasing pre-load on ventricular output and ejection in man. Circulation 1980;62:535-41

13 Daughters GT, Derby GC, Alderman EL, et al. Independence of left ventricle pressure-volume ratio from pre-load in man early after coronary artery by-pass graft surgery. Circulation 1985;71:945-50.

14 Manders WT, Vatner SF. Effects of sodium penthobarbital anesthesia on left ventricular function and distribution of cardiac output in dogs, with particular reference to mechanism for tachycardia. Circ Res 1976;39:512-6.

15 Spirito P, Maron BJ. Doppler echocardiography for assessing left ventricular diastolic function, Ann Intern Med 1988;109:122-6.

16 Lew WYW. Evaluation of left ventricular diastolic function. Circulation 1989;79:1393-97.

17 Appleton C, Hatle L Popp R. Relation of transmitral flow velocity patterns to left ventricular diastolic function: new insights from a combined haemodynamic and Doppler echocardiography study. $f$ Am Coll Cardiol 1988;12: 426-40.

18 Hatle L. Ventricular diastolic function: Possibilities and limitations of noninvasive assessment by Dopple

19 Zogbi W, Bolli R. The increasing complexity of assessing diastolic function from ventricular filling dynamics. $\mathcal{F} \mathrm{Am}$ Coll Cardiol 1991;17:237-8.

20 Weiss JL, Frederiksen JW, Weisefelt MLJ. Hemodynamic determinants of the time course of fall in canine left ventricular pressure. Clin Invest 1976;58:751-76.

21 Raff GL, Glantz SA.Volume loading slows left ventricular isovolumic relaxation rate-evidence of load dependent relaxation in the intact dog heart. Circ Res 1981;48: 813-24

22 Freeman GL, Little WC, O'Rourke RA. Influence of hear rate on left ventricular performance in conscious dogs. Circ Res 1987;61:455-62.

23 Bianco JA, Filiberti AW, Baker SP, et al. Ejection fraction and heart rate correlate with diastolic peak filling rate at rest and during exercise. Chest 1985;88:107-14.

24 Appleton CP. Influence of incremental changes in hear rate on mitral flow velocity: assessment in lightly sedated conscious dogs. F Am Coll Cardiol 1991;17:227-36.

25 Stoddard MF, Pearson AC, Kern MJ, et al. Left ventricula diastolic function: Comparision of pulsed Doppler echocardiographic and hemodynamic indexes in subjects with and without coronary artery disease. $f \mathrm{Am}$ Coll Cardiol 1989;13:327-36.

26 Courtois M, Vered Z, Barzilai B, et al. The transmitra ressure-flow velocity relation Circulation 1988;78: 1459-68.

27 Calvin JE, Dridger AA, Sibbald WJ. Does the pulmonary capillary wedge pressure predict left ventricular preload in critically ill patients? Crit Care Med 1981;9:437-43.

28 Brutsaert DL, Rademakers FE, Sys SU. Triple control of relaxation: implications in cardiac disease. Circulation 1984;69:190-6.

29 Gaasch WH, Blaustein AS, Andrias CW, et al. Myocardial relaxation. II. Hemodynamic determinants of rate of left ventricular isovolumic pressure decline. Am $f$ Physiol 1980;239:H1-H6.

30 Ishida Y, Meisner J, Tsujioka K. Left ventricular filling dynamics: influence of left ventricular relaxation and left atrial pressure. Circulation 1986;74:187-96.

31 Nishimura RA, Abel MD, Hatle LK, et al. Significance of Doppler indices of diastolic filling of the left ventricle: Comparison with invasive hemodynamics in a canin model. Am Heart f 1989;118:1248-58.

32 Choong C, Abscal V, Thomas J. Combined influences of ventricular loading and relaxation on the transmitral flow velocity profile in dogs measured by Doppler echocardiography. Circulation 1988;78:672-83.

33 Triulzi MO, Castini D, Ornaghi M, et al. Effects of preload reduction on mitral flow velocity pattern in normal subjects. Am f Cardiol 1990;66:995-1001.

34 Tak T, Choudhary RS, Chatterjee S, et al. Effect of loading conditions on Doppler-derived transmitral flow indices in normal subjects and patients with coronary artery disease. Echocardiography 1992;9:467-74

35 Leite-Moreira AF, Gillebert TC. Nonuniform course of left ventricular pressure fall and its regulation by load and contractile state. Circulation 1994;90:2481-91.

36 Gaasch WH, Levine HJ, Quinones MA, et al. Left ventricular compliance: Mechanisms and clinical implications. Am f Cardiol 1976;38:645-53.

37 Glantz S, Misbach G, Moores Y. Factors which affect the diastolic pressure-volume curve. Circ Res 1978;42. 171-80.

38 Nishimura RA, Abel MD, Hatle LK, et al. Assessment of diastolic function of the heart: Background and current applications of Doppler echocardiography. Mayo Clin Proc 1989;64:181-204

39 Louie E, Rich S, Levitsky S, Brundage B. Doppler echocardiographic demonstration of the differential effects of right ventricular pressure and volume overload on left ventricular geometry and filling. F Am Coll Cardiol 1992, 19:84-90.

40 Yamagishi T, Uki K, Yamauchi M, et al. Acute effects of sublingual isosorbide dinitrate on global and regional left ventricular diastolic filling in normal persons. Am Cardiol 1986;58:1061-66.

41 Choong CY, Abascal VM, Thomas JD, et al. Combined influence of ventricular loading and relaxation on the transmitral flow velocity profile in dogs measured by Doppler echocardiography. Circulation 1988;78:672-3.

42 Marmor A Krakaner J, Schnecweiss A. Effects of a single dose of isosorbide-5-mononitrate on left ventricle diastolic function in systemic hypertension. $A m \mathcal{F}$ Cardiol 1989;63:1235-39.

43 Hargreaves $\mathrm{AD}$, Muir AL. Hemodynamic responses to glyceryl trinitrate: influence of rate and duration of delivery. Eur Heart $\mathcal{\exists} 1992 ; 13: 960-5$.

44 Ludbrook PA, Byrne JD, McKnight RC. Influence of right ventricular hemodynamics on left ventricular diastolic pressure-volume relation in man. Circulation 1979;59: 21-31.

45 Lavine SJ, Campbell CA, Held AC, et al. Effect of nitroglycerin induced reduction of left ventricular filling pressure on diastolic filling in acute 